\title{
MEMÓRIA LITERÁRIA, LEITURA E ENSINO
}

LITERARY MEMORY, READING AND TEACHING

Guaraciaba Micheletti*

Universidade de São Paulo, São Paulo, SP, Brasil

Universidade Cruzeiro do Sul, São Paulo, SP, Brasil

Ana Elvira Luciano Gebara**

Universidade Cruzeiro do Sul, São Paulo, SP, Brasil

Fundação Getúlio Vargas, São Paulo, SP, Brasil

Resumo: 0 ensino da literatura mesmo quando centrado na leitura é, muitas vezes, negligenciado diante de outras necessidades da sala de aula. Privilegia-se o ensino da leitura, sem objeto bem definido, por se apresentar como uma preocupação de todas as áreas e não somente das aulas de língua materna. Porém, um olhar mais atento revela que é exatamente a leitura dos textos literários que traz respostas para questões de outras esferas (LAJOLO, 1982; 1993; COSSON, 2006). Neste artigo, tomando como base, a intertextualidade, um dos elementos constitutivos dos textos literários (MAINGUENEAU, 2004), propõem-se algumas reflexões sobre o papel do letramento literário, apresentando sugestões de atividades, baseadas no conceito de professor como mediador dos diálogos consituídos no texto literário e de outros diálogos derivados destes na sala de aula.

Palavras-chave: Leitura; Letramento literário; Intertextualidade; Ensino de literatura.

Abstract: The teaching of literature even when focused on reading is offen overlooked in the face of other classroom needs. The teaching of reading, without well-defined object, is emphasized by performing as a concern of all areas and not only in mother-tongue classes. However, a closer look reveals that this is exactly the reading of literary texts that provides answers to questions from other spheres (LAJOLO, 1982; 1993; COSSON, 2006). In this article, taking as a basis, the intertextuality, one of the consitivent elements of literary texts (MAINGUENEAU, 2004), we propose some reflections on the role of literary literacy by presenting suggestions for activities, based on the concept of teacher as mediator of the dialogues conssituted in the literary text and other derivatives of these dialogues in the classsoom.

Keywords: Reading; literary literacy;; Intertextuality; Teaching of Literature.

* Professora da Universidade de São Paulo - USP / Universidade Cruzeiro do Sul - UNICSUL, São Paulo, Brasil; guatti@uol.com.br

** Professora da Universidade Cruzeiro do Sul - UNICSUL, São Paulo, Brasil / Fundação Getúlio Vargas, São Paulo, Brasil; aegebara@hotmail.com 
Linha D'Água (Online), São Paulo, v. 29, n. 1, p. 85-102, jun. 2016

\section{Introdução}

O ensino da leitura tem sido, ao longo das últimas décadas, focalizado, dir-se-ia à exaustão, e, mesmo assim, não se conseguiram, ainda, os resultados esperados pelos responsáveis pelo ensino e pela sociedade, em geral. A leitura não proficiente continua sendo o calcanhar de Aquiles do ensino de língua portuguesa. Hoje, com os avanços dos estudos linguísticos, tornou-se comum, no discurso dos materiais didáticos e instrucionais, uma apologia ao ensino dos gêneros e de textos das mais diferentes esferas, mas a prática nem sempre está aliada a esse discurso.

Os alunos apresentam déficits nas várias disciplinas que compõem a grade curricular e, com frequência, por má interpretação dos textos que circulam no ambiente escolar e que compõem um acervo mínimo (e esperado) de leitura. O que se ouve ao longo do tempo é que o aluno "não sabe português" e, por isso, não consegue aprender as demais disciplinas.

Em primeiro lugar, deve-se considerar que todo professor é um professor de leituras, assim mesmo, no plural. Cada disciplina do currículo tem seus textos didáticos - ou não - com suas particularidades que precisam ser comentadas pelo professor que exerce a função de mediador. Dessa forma, ler na aula de matemática é diferente de ler na aula de Ciências, que é diferente de ler na aula de artes, e assim por diante. Cada área presente na escola exige que o aluno acione conhecimentos textuais (textos de problemas, expositivos, com imagens, e outros) e linguísticos, além dos conhecimentos de mundo que o colocam em diferentes posições em relação aos objetos estudados e a outros que estão do lado de fora dos muros da escola (KOCH; ELIAS 2006; LAJOLO, 1993).

Ao lado dessa situação, há outro acomodamento em relação à leitura que passa, muitas vezes, por processo apenas de aprendizagem de código. Quando o aluno passa a descodificar, o trabalho do ensino de leitura estaria concluído. Essa concepção não poderia estar mais afastada da realidade e é por isso que se ouve comumente: "o aluno lê, mas não entende". Se o aluno descodifica, mas não entende, isso pode significar que ele não conseguiu recuperar o contexto em que se produziu o texto; a função do gênero que esse texto materializa; o papel da estrutura composicional (questões gramaticais e derivadas, por exemplo, do uso de linguagens específicas ou variantes linguísticas; da organização da frase e dos períodos etc.); e o tratamento da temática que envolve escolha vocabular, estabelecimento de ponto de vista e afins.

A leitura vista sob essa concepção é múltipla e apresenta diferentes objetivos. Para cada um deles, uma série de estratégias é acionada e precisa ser apresentada aos alunos na escola. Dentre os textos que são mencionados como fonte de insucesso no espaço escolar, estão os literários, em prosa e em verso. Se nos 
Linha D'Água (Online), São Paulo, v. 29, n. 1, p. 85-102, jun. 2016

perguntarmos quando essa relação se estabelece, temos de começar pela pergunta "onde está a literatura?".

Embora não se atribua ênfase ao conteúdo da esfera literária, os textos dessa área estão presentes na escola desde os primeiros passos do aluno. São as cantigas infantis e as histórias que vão povoando o imaginário das crianças. Não existe, porém, uma consciência do que seja o trabalho com a literatura na escola, pois, nessa fase, é o caráter lúdico que traz o texto para as aulas. No entanto, há diversos efeitos "colaterais" resultantes da leitura dos textos literários. Um deles é o trabalho linguístico, que a criança percebe na repetição e na memorização de trechos e textos brincando com as palavras e sua organização. Outro é a discussão de temas que proporcionam ora conflitos ora conforto ao leitor mirim - embates ou encontros com outras visões, a do autor e a do grupo. São esses os efeitos que podem ser chamados ainda de secundários que também merecem a atenção do professor para a estruturação do trabalho com o literário.

Quando a literatura chega às séries intermediárias do Ensino Fundamental, de modo especial a partir do $5^{\circ}$ ou $6^{\circ}$ ano, os textos literários, presentes nos livros didáticos, começam a fazer parte de seu cotidiano, quase sempre, para atividades de compreensão e para o ensino das unidades gramaticais do Programa adotado. A leitura interpretativa, aquela em que o aluno pode colocar-se, respeitando os limites do texto, ocorre mais raramente. Essa postura em sala de aula é observada não somente no Brasil, como também em outros países como a França ${ }^{1}$. Trata-se de uma atribuição de objetivo a textos que não se fecham em metas definidas externamente. A leitura do texto da esfera literária passa a ser uma espécie de charada na qual o que se busca é encontrar a chave de compreensão que o professor detém.

Ainda no Fundamental II, é notória a afirmação de que os alunos não leem. Com muita frequência solicita-se, quase para cumprir uma formalidade, que leiam obras infanto-juvenis o que, via de regra, ocorre de dois modos: o tradicional, quando os alunos leem e devem responder a questionários e realizar resumos, fichas de leitura etc.; outro, tido como moderno e avançado, no qual os alunos escolhem livremente suas leituras extraclasse e, praticamente, nada é feito com essas possíveis leituras. Pode-se notar que ambas as modalidades apresentam deficiências: a primeira prende-se ao decorar, ao copiar resumos, sem que a obra tenha realmente sido lida; a segunda, também não garante que tenha ocorrido a leitura; em ambas, fica a inexistência de uma reflexão sobre o texto. $\mathrm{E}$ os alunos não leem mesmo? Essa afirmação é cada vez mais falaciosa: eles leem o que lhes interessa e não o que

Cf. NEVES, C. A. de B. A Literatura no ensino médio: os gêneros poéticos em travessia no Brasil e na França. Tese de Doutoramento. IEL - UNICAMP, Campinas, 2014. 
Linha D'Água (Online), São Paulo, v. 29, n. 1, p. 85-102, jun. 2016

a escola pretende que seja lido. Deve-se, então, substituir os textos solicitados por aquilo que interessa às crianças e aos adolescentes? Definitivamente, não. São dois trabalhos com leituras que a escola precisa realizar paralelamente. É preciso não esquecer que as obras literárias, sem proselitismo, carreiam experiências e trazem informações que serão necessárias à formação de um leitor mais competente.

É na literatura que são exploradas todas as potencialidades da palavra, da língua, para dar existência a seres imaginários que suprem as necessidades de expressão de nossas mentes. Por meio da literatura, o ser humano pode, confortavelmente, vivenciar experiências ${ }^{2}$ sem os perigos do mundo real e transformá-las para construir-se.

Aulas de literatura que trazem informações sobre os períodos, as conhecidas escolas literárias, suas características, acabam por não contemplar uma experiência de leitura que o texto literário pode proporcionar como a descrita acima. O que pode ser feito então? Em primeiro lugar, as leituras do texto literário precisam constar do planejamento; devem proporcionar a experiência com um cânone, definido a partir de outras instâncias além da escola que constituem, ao lado desta, a esfera literária, como a crítica literária do país; corresponder aos objetivos do projeto de cada nível; adequados à idade pela temática com vistas à formação do aluno. Para isso, um primeiro passo é o de criar uma motivação nos alunos. Depois, quando a leitura tiver sido realizada, promover uma troca de experiências e/ ou informações entre os alunos. A troca de experiências, em geral, vem carregada de informação e vice-versa, uma vez que não é possível fazer a distinção entre o que se aprende cognitivamente e o que se imprime em termos emocionais diante das situações abordadas nos romances, contos, poemas, crônicas e afins ${ }^{3}$. Nessas atividades, o professor se posiciona sempre como um emulador de questões e moderador das trocas. Então o texto na sala de aula é sempre um pretexto? Claro que sim, e deve ser um bom pretexto para reflexão e aprendizagem, como afirma Lajolo (1993, p. 15): "Ou o texto dá um sentido ao mundo, ou ele não tem sentido nenhum. E o mesmo pode se dizer de nossas aulas".

2 A palavra experiência ou sua forma plural vem sendo e será reiterada neste artigo, por acreditarmos que, na leitura, em especial na dos textos literários, faz-se necessário uma espécie de corpo a corpo com o texto para extrair dele todas as suas virtualidades e poder fruí-lo.

3 Alinhamo-nos aqui com as etapas que Cosson apresenta em Letramento literário: teoria e prática (2006), pois, como aponta o autor, "na escola é preciso compartilhar a interpretação e ampliar os sentidos construídos individualmente. A razão disso é que, por meio do compartilhamento de suas interpretações, os leitores ganham consciência de que são membros de uma coletividade e de que essa coletividade fortalece e amplia seus horizontes de leitura" (COSSON, 2006, p. 65). 
Linha D'Água (Online), São Paulo, v. 29, n. 1, p. 85-102, jun. 2016

No Ensino Médio, a Literatura é um dos temas de língua portuguesa. Por vezes, as escolas a colocam como uma das disciplinas dessa área; o que, nem sempre, resulta em uma abordagem mais adequada. Dentre elas, a mais comum, de conteúdo tradicional, privilegia, quase que exclusivamente, os períodos - as escolas literárias. Nessa abordagem, observa-se um deslocamento da busca de sentidos do texto para o contexto de produção. Trata-se, portanto, de uma forma de explicar as obras literárias como reafirmação do que se encontra(va) na sociedade. Essa chave de compreensão do literário é relevante, mas não explicita o diálogo constante que as obras realizam com o passado e o futuro, em vetores de duas direções - aproximando tempos e espaços.

Sem dúvida, há que existir uma contextualização que envolva os fatos históricos, tanto científicos como sociais e culturais, uma vez que tudo está interligado e responde por uma visão de mundo numa determinada época. Apresentar esses dados em teia não significa fazer uma lista de elementos que as obras mais típicas de cada experiência estética propunham. Trata-se de entrelaçar o que ocorria e como se representava esse ocorrido - entender como eram os caminhos dados aos contemporâneos do escritor, com quem esse autor dialogava, a quem se opunha, o que declarava. Um exemplo é a obra de Camões. Há poemas do autor português que são mais facilmente compreendidos pela temática, por exemplo, do sofrimento amoroso. Mas, mesmo nesses, existe, além dos traços do tempo e espaço, um trabalho com a linguagem, no sentido mais amplo, que também traz as marcas de seu tempo e a leitura que, nesse caso, o poeta fez das tradições e da realidade de sua época. Ou seja, a expressão de um autor ou de um povo prende-se à história pessoal e à coletiva e precisamos encontrar no texto esses elementos que se abrem a essas conversas infindáveis, as que serão feitas enquanto houver leitores para o texto.

$\mathrm{Na}$ segunda metade dos anos 90, os PCN trouxeram, do ponto de vista de concepções e indicações de trabalho, avanços bastante significativos. Deslocava-se a apresentação de escolas literárias em períodos para um trabalho com as temáticas, indicando outras aproximações possíveis para o literário. Nesse caminho, gostaríamos de apresentar o trabalho com as obras literárias em prosa e em verso. Principalmente, porque, como em outros domínios sociais, os textos são realizações de gêneros e estes são fruto de um trabalho intenso entre tradição e inovação (MARCUSCHI, 2010). Gêneros como o romance (dos mais variados tipos), a crônica, sonetos, canções, contos têm uma história e cada um dos autores e poetas, cujos textos materializam esses gêneros, travaram um embate com as regras e as possibilidades de ampliação e deslocamento desses parâmetros de composição. Muitas vezes, esses autores se opuseram a tudo que existia antes; outras renderam homenagens a outros períodos, no entanto, cada um de seus textos refletiu essa 
Linha D'Água (Online), São Paulo, v. 29, n. 1, p. 85-102, jun. 2016

relação que se sedimenta entre as linhas da escrita literária. Ler uma obra literária é ler a voz do escritor, ler a história dos gêneros e ler a voz do homem na História.

Como afirma Cosson, "no ambiente escolar, a literatura é o lócus do conhecimento. (2006, p. 26)" Assim, à escola cabe organizar a atividade de leitura de textos literários para que ela cumpra seu papel na formação humanística do aluno. É preciso que se estabeleçam objetivos claros e que eles sejam perseguidos desde a seleção de algumas obras representativas da tradição cultural à maneira de abordá-los com os alunos para que se ensejem momentos de reflexão que possam, no futuro, transformar a leitura em conhecimento. Atualmente, dá-se o nome de letramento literário à atividade em que o leitor adquire o domínio da leitura do texto literário. Nas palavras de Steiner (1988, p. 28) trata-se da "alfabetização humanista" Para ele, a leitura é uma forma de atuação. Para ele, "é tarefa da crítica literária nos ajudar a ler como seres humanos completos, dando exemplo de precisão, medo e deleite." (1988, p. 29) Para nós, é tarefa da escola e do professor intermediar a leitura literária, auxiliando o aluno a dar seus primeiros passos, como uma criança que aprende a andar, tropeçando aqui e ali até caminhar e escolher seus caminhos.

\section{Mas como auxiliar nesses primeiros passos?}

Acreditamos que o professor necessite ter consciência de que ele é, antes de tudo, um mediador, a quem cabe buscar o caminho com muita leitura, muita vivência, compreensão e desejo de tornar-se melhor. Enfim, é necessário correr riscos. Nosso propósito não é o de apresentar uma receita pronta e acabada. Mesmo as melhores receitas dependem das mãos de seus executores ${ }^{4}$.

Os textos literários podem se apresentar, atualmente, em configurações diversas das do passado, porém nessas novas formas e funções que são postas diante de nós, como o microconto, a twitteratura ou ainda o poema com traços da prosa, ouve-se o diálogo com o passado. Os gêneros literários se dividiam em lírico, épico e dramático (STAIGER, 1975) e, com o passar dos séculos, as configurações sociais e estéticas promoveram a passagem do caráter substantivo desses termos para um caráter adjetivo. Isso significava que mais do que classificações o que se tornara importante para os estudos literários eram as propostas que cada autor fazia para o seu tempo em diálogo com outros, em busca da expressão de seus anseios, angústias, certezas e incertezas - daí o elemento constitutivo da literatura: a polissemia.

4 O artigo alia a experiência em sala à pesquisa acadêmica no projeto "Estilística e ensino", do Programa de Mestrado em Linguística da Universidade Cruzeiro do Sul, que se ocupa, entre outras questões daquelas que relacionam leitura, estilística e gêneros de diferentes esferas. 
Linha D'Água (Online), São Paulo, v. 29, n. 1, p. 85-102, jun. 2016

Desde o princípio (que identificamos na Antiguidade grega, mas que pode abarcar outras antiguidades), a arte que trabalha com o verbal preconiza o uso consciente $\mathrm{e}$ desafiador, criativo e propositivo, de rupturas e de retomadas da língua, dos temas de cada época e de como eles são tratados. Para transformar esses elementos em objetos didáticos, os textos literários saem de uma circulação externa à escola, para nela, serem, muitas vezes, contidos em interpretações autorizadas. Nos anos de repressão (houve vários desses períodos no Brasil), havia nos livros uma indicação de como ler os textos literários. Em outros períodos, pela visão que tínhamos dos jovens e do compromisso que assumíramos com eles, a repressão não era gerada de forma externa, representava, porém, uma visão de mundo que queríamos que os jovens assumissem. E o texto literário se presta a essas posturas? Mesmo em face de condutas redutoras, esses textos se libertam e produzem aquilo que havia como uma espécie de objetivo do texto: os sentidos se manifestam; surdem nos textos e novamente a obra diante dos alunos é digna de ser ouvida e lida.

Quando se trabalha com os períodos como já se apontou anteriormente, há um desgaste e um descrédito generalizado que se espalha entre os alunos. Isso ocorre porque obras como Memórias de um Sargento de Milícias, não se enquadram perfeitamente nos moldes apontados para a época em que foi escrito: como se as personagens se rebelassem contra as "normas" estéticas esperadas para aquele período. Como a literatura trata da experiência humana, uma maneira adequada de se abordar os textos literários é buscar as relações possíveis entre eles - daí um primeiro caminho para explicitar essas relações entre tempos e espaços pode ser o estudo das manifestações da intertextualidade.

\section{A intertextualidade como estratégia de leitura dos textos literários}

A intertextualidade, segundo Maingueneau, pode ser compreendida como um processo constitutivo dos textos ou como "um conjunto de relaçóes explícitas ou implícitas que um texto ou um grupo de textos determinado mantém com outros textos $(2004, \text { p. } 288)^{5}$. O que implica conceber o texto como um sistema aberto com traços de outros textos que são incorporados em sua constituição como repetição e transformação. Os processos de intertextualidade variam conforme as características, necessidades, funções e configurações de cada gênero e de cada campo de ação. Assim o discurso científico utiliza a intertextualidade para comprovar procedimentos e para argumentar em favor de uma ou outra posição, buscando sempre

5 Grifos do autor 
Linha D'Água (Online), São Paulo, v. 29, n. 1, p. 85-102, jun. 2016

a forma explícita da citação. Já o discurso publicitário promove as relações entre os textos para obter a adesão do leitor por meio de alusões, paródias e afins para acessar a memória discursiva e as imagens que as relações entre os textos podem trazer para favorecer o produto. Nesse artigo, tomamos o conceito de intertextualidade conforme essa segunda posição, principalmente pelo fato de que esse conceito surgiu para o estudo dos textos literários com Kristeva (1979) e indica a relação estreita entre tradição e inovação que ocorre nessa esfera (ALFARO, 1996).

É possível relacionar os textos de forma explícita (citações diretas ou indiretas com identificação) ou implícita (alusões, paródias, paráfrases). O efeito desse conjunto de relações entre os textos pode ser de adesão (homenagens, estilizações) ou de refutação (paródia, sátira etc.) (BENTES, KOCH, CAVALCANTE, 2012). Em ambos os casos, o leitor deve acionar a memória discursiva e seu conhecimento de mundo e de texto relevantes para que a leitura explicite os pontos de contato e os efeitos de sentido decorrentes desses pontos.

Uma das tarefas do professor é mediar o reconhecimento desses fios que ligam textos de diferentes épocas, autores, gêneros. Como se trata de relações constitutivas do texto literário, a intertextualidade permite que se elaborem projetos que se adequem às noções de escolas e períodos, mostrando como os textos se relacionam de forma mais ampla. Dependendo do interesse das turmas e dos gêneros trabalhados nas aulas de produção textual e em outras disciplinas, é possível traçar as relações intertextuais em atividades que reúnem textos de outras esferas. Como é possível observar em Bandeira que, muitas vezes, utilizou esse recurso fazendo alusões a si mesmo e a outros autores. No primeiro caso, ele faz dialogar, em Libertinagem, "Teresa" e "Madrigal tão Engraçadinho". O poema "Teresa", por sua vez, já mantinha relação intertextual com o poema "O adeus de Teresa”, de Castro Alves. A relação que o eu lírico mantém com as "Teresas" é uma possibilidade de análise das representações de mulher e das relações amorosas no século XIX e na década de 30 do século XX.

Existe um confronto, uma espécie de jogo que se estabelece entre dois ou mais textos; e a significação do novo se produz no espaço desse jogo. Desse modo, o primeiro diálogo que se estabelece consiste naquele que se dá na ocasião em que se altera a situação: leitura na sala de aula. $\mathrm{O}$ domínio pleno dessa circunstância pelo professor pode resultar em estratégias mais adequadas de abordagens. Posteriormente, dentro do próprio texto, podem-se considerar os vários discursos que o compõem, desde os slogans aos fragmentos literários.

Usar um texto como pretexto não é privilégio da escola. No limite, podemos dizer que até mesmo os críticos literários sempre usam os textos de outrem como pretexto para falar de si, para expressar-se. Sem caminharmos tão longe, podemos 
Linha D'Água (Online), São Paulo, v. 29, n. 1, p. 85-102, jun. 2016

observar que a nossa história de leituras (conceito 'tão em moda!') direciona a nossa produção. Observemos Cota zero, de Carlos Drummond de Andrade:

Stop.

A vida parou

Ou foi o automóvel? (1988, p. 26)

O poema, publicado em Alguma Poesia, 1930, tem sido objeto de muitas interpretações. Num primeiro olhar, chama-nos a atenção o termo inglês que indica uma parada. Depois a pergunta que parece embutir uma resposta, embora essa resposta deva ser objeto de interpretação. O título já apela para o inusitado, a cota, que indica uma quantidade, se esvazia em presença do determinante zero. As rupturas linguísticas do termo estrangeiro e do paradoxo contribuem para um tom irônico que se identifica naqueles três versos.

Sessenta e dois anos depois, janeiro de 1992, Cota zero aparece como o título de uma crônica de Otto Lara Resende ${ }^{6} \mathrm{O}$ diálogo com o poema de Drummond é evidente nas duas frases finais ("Stop. Foi o futuro que chegou, ou o Brasil que parou?”). Prestou-se à construção de uma crônica bem humorada a propósito da frustrada expectativa sobre o crescimento populacional brasileiro e, de quebra, sobre vários aspectos da vida cotidiana nesta República. A mesma ironia do poeta 'gauche'. Se concordarmos com Riffaterre que a representação cria a coisa representada e que uma sequência verbal, colocada no princípio de texto, 'motiva' todas as demais (RIFFATERRE, 1970), percebemos que a crônica não herda apenas a ironia drummondiana, mas se estrutura num diálogo com toda uma tradição, representada pelos fragmentos que vão pontuando a composição de Lara Resende.

Os textos revisitados têm origens em gêneros diversos e também são aproveitados de modos diferentes. Vejamos alguns, além de Cota zero. Evoca-se a segunda parte de $A$ noite dissolve os homens, do próprio Drummond (1988, p. 70-71) e os fragmentos de um poema de tom dramático passam, pela mudança de contexto, a soar ironicamente. Bilac surge com o seu ufanismo de poeta oficial: Pátria, latejo em ti! Joga-se com o ditado popular, mais vale um pássaro na mão do que dois voando. Lembra-se o texto legal: a Constituição, rememoram-se nomes muito conhecidos de nossa tradição literária e da música popular. Enfim esses fragmentos, essas lembranças, que revelam uma história de leituras, uma história de vida, são os

$6 \quad$ Cf. Anexo

MICHELETTI, G; GEBARA, A. E. L. Memória literária, leitura e ensino 
Linha D'Água (Online), São Paulo, v. 29, n. 1, p. 85-102, jun. 2016

constituintes da crônica de Otto Lara Resende. Mais que um modo de dizer, esses fragmentos constroem $o$ dizer.

Além das citações diretas de trechos de poemas e de referências a poetas da tradição (Bandeira, Murilo Mendes) e do cancioneiro popular (Noel Rosa), trechos como "O penumbrismo, a tristura decadentista, isto era coisa do passado até nas artes e nas letras, de súbito despertadas em 1922" remetem a aspectos de movimentos literários que podem ser explorados pelo professor de diferentes maneiras. É possível trazer-se para a sala de aula fragmentos de textos que focalizem posturas artísticas tão diversas e contextualizá-las e, ainda, compará-las a outros momentos da história literária no século XX.

Quem poderia afirmar que esta crônica não é um bom "pretexto" numa sala de aula? Sem dúvida ela não foi escrita com esse objetivo, não é um texto didático, não tem como interlocutor, imaginado no momento de sua feitura, o educando. Foi elaborada para integrar uma página jornalística, obedecendo a um princípio básico de sua forma: trata de um assunto do cotidiano; o contexto imediato era o fato de que alguns prefeitos estavam reclamando do Censo do IBGE, cujos resultados demonstravam que, em seus municípios, havia decrescido o número de habitantes, acarretando uma diminuição das verbas repassadas pelo Governo Federal.

Para ir fundo na leitura deste texto, faz-se necessário recorrer à história literária, saber pelo menos um pouco do contexto histórico social e das idiossincrasias da cosmovisão dos autores citados. Pode-se observar o nível de linguagem que predomina na forma da crônica, e como Otto Lara Resende passeia entre o tom descontraído de uma conversa e a seriedade de uma reflexão, sem abrir mão de um registro afetivo.

Como convém a uma crônica, o texto se inicia num tom de conversa, com expressões e termos próprios da língua falada que predomina em todo o primeiro parágrafo: "outro dia mesmo", "Deu até manchete", "botava banca", e permanece no início do segundo. Depois, palavras mais eruditas: "pulsava", "vislumbrava", "miragem" e muitas outras, passam a pontilhar o texto. Estudar-se o efeito irônico desse contraste pode, além de ampliar o vocabulário dos alunos, dar-lhes consciência da adequação e da expressividade de certos usos da linguagem. Em outras palavras, estudar os níveis de linguagem desse texto, seria, salvo melhor juízo, um ótimo pretexto. Observar a configuração do sujeito do texto pode, também, ser um recurso interessante para tratar da adequação da linguagem. Por meio de dêiticos como "aqui", "a gente", o autor demonstra um grande envolvimento com a narrativa. É alguém que fala por experiência e memória, o que é típico do gênero crônica, mas não se adequaria a um texto do livro didático de História.

Por outro lado, um confronto com os textos citados pode servir não apenas para situar escolas literárias, um dos objetivos do ensino médio, mas trabalhar as 
Linha D'Água (Online), São Paulo, v. 29, n. 1, p. 85-102, jun. 2016

diferentes visões em seus contextos históricos - aspectos ideológicos, políticos, sociais, posição do enunciador (autor do texto). Em outras palavras, seria possível e aconselhável uma espécie de análise do discurso de Cota zero de Otto Lara Resende e dos vários fragmentos citados. Além, é claro do cotejo (inclusive em relação à época da escrita) com o poema inspirador da crônica.

$\mathrm{E}$ as questiúnculas gramaticais? Não precisamos ignorá-las. Podemos partir dos processos coesivos do texto para um estudo morfossintático (sequências justapostas, alguns conectivos, pronomes que promovem a retomada de elementos anteriores e que conduzem a uma progressão temática). ${ }^{7}$ Outra questão que pode ser suscitada é: como fragmentos tão diversos compõem um todo harmônico? A crônica de Lara Resende se apoia em advérbios, seria bastante producente observá-los nesse contexto. De novo insistimos no seu papel de gerador de sentido, mesmo que essa classe seja descrita como de palavras gramaticais, desprovidas de significação externa. Ainda, para não abandonar o estudo de classes de palavras, poder-se-ia observar os verbos, tanto do ponto de vista semântico, como formal e associá-los à organização textual (enquanto uma fôrma) e também à significação dessa crônica. É possível ainda focalizar a sintaxe. Frases curtas, frases nominais, frases com predicados nominais, observando sempre a estrutura em função de sua expressividade. É possível verificar como se construiu linguisticamente esse patchwork de palavras.

Em resumo: é possível estudar língua e literatura utilizando um texto como esse, e esse estudo não é bom pretexto para, é o que constitui os sentidos desse texto. Nesse ponto, surge a grande interrogação de todos nós: o que é uma leitura adequada?

Para nós, a leitura adequada é aquela possível e condicionada pela estrutura do texto, pelas condições histórico-sociais de sua produção e de sua recepção, pela formação do leitor e, no caso específico da escola, pelo leitor-mediador. Trabalhar com textos requer estar atento à rede de significações que se estabelece no embate de vários fragmentos que os constroem.

Observando os temas que são importantes ou despertam interesses nas turmas em que trabalha, o professor pode criar atividades para que a leitura literária possa acontecer e o trabalho com os textos seja significativo além do caráter obrigatório sempre presente no espaço escolar. Essas atividades podem ter variadas conformações. Uma delas é colocar lado a lado poemas de um mesmo autor verificando os traços que são frequentes e que identificam seu modo de representar o mundo e seus temas. Uma sugestão é escolher poemas de diferentes livros para poder identificar esses traços presentes, pode ser Manuel Bandeira, Cecília Meireles, Carlos

7 Para as questões de ensino de gramática, cf. TRAVAGLIA, L. C. (2002) Gramática e interação: uma proposta para o ensino da gramática no $1^{\circ}$. e $2^{\circ}$. Graus. 8 ed. São Paulo: Cortez. 
Linha D'Água (Online), São Paulo, v. 29, n. 1, p. 85-102, jun. 2016

Drummond de Andrade, Manoel de Barros, Paulo Leminski entre outros. A escolha deve ser feita com base nos interesses da sala e no projeto do professor. No momento da escolha dos poemas e do levantamento dos dados, é necessária a consulta a textos da crítica literária para que o maior número de leituras possa ser aproveitada e oferecida aos alunos sem, no entanto, reprimir as leituras que eles farão.

Outra sugestão é reunir poemas de diferentes autores contemporâneos sobre um mesmo tema. Esse olhar sincrônico permite da mesma forma que o anterior que sejam identificados diversos tratamentos do tema de acordo com diferentes perspectivas. A escolha do tema nesse caso é crucial para o desenvolvimento bem sucedido da atividade, uma vez que se o tema não chamar a atenção, provavelmente a adesão à atividade será pouco significativa. Temas como o amor, a relação amorosa, a guerra, o futuro, a vida, são sempre caros aos alunos principalmente nessa faixa da escolaridade (Ensino Médio) em que eles estão, já que devem escolher uma carreira, buscar perspectivas de colocação social e amadurecimento pessoal.

\section{Uma proposta a partir de um eu lírico feminino: diálogo entre mulheres à espera}

Além dessas sugestões que sempre poderão ser acrescidas por outras suscitadas pelo trabalho com as turmas, delineamos uma atividade que pode ser desenvolvida em sala. Trata-se da leitura comparada de poemas com o tema da mulher, sua posição e relações na sociedade: três poemas podem ser os gatilhos iniciais - uma Cantiga de Amigo, de Dom Dinis "Ai flores, ai flores do verde pino", o poema "Leito de folhas verdes" de Gonçalves Dias e "As penélopes urbanas não têm ajuda dos deuses", de Alberto da Cunha Melo. Esses poemas trazem três diferentes representações de mulher, na configuração de eu lírico feminino. Com eles, é possível discutir qual o papel da mulher, como ela se coloca e o que se espera dela socialmente. Para os alunos, pode ser uma oportunidade para que apresentem suas visões sobre a mulher e, a partir dessa leitura, delinear a imagem da mulher hoje. Para essa segunda etapa, outros textos podem ser lidos, não somente os verbais, mas também os multimodais (como as propagandas impressas e de televisão; filmes, canções etc.).

O primeiro poema sugerido, facilmente localizado nas páginas da Internet ${ }^{8}$, é uma cantiga de amigo e faz parte da lírica medieval galego-portuguesa. Tratase de uma composição breve e singela, cuja voz é de uma mulher apaixonada. A

8 No site Cantigas medievais galego-portuguesas: http://cantigas.fcsh.unl.pt/cantiga. asp? cdcant=592 Acesso em 06-04-2014. 
Linha D'Água (Online), São Paulo, v. 29, n. 1, p. 85-102, jun. 2016

palavra "amigo" tem um sentido diverso do hoje utilizado: é o namorado, o amante. Embora os poetas medievais fossem homens, nesses poemas, utilizavam um enunciador feminino como ocorre até em nossos dias?.

Essas composições seguem um modelo da lírica trovadoresca portuguesa, como as cantigas de amor (em que o enunciador é o homem que fala a sua amada) são estruturadas a partir de paralelismos e refrãos ainda que com um vocabulário mais simples e repetitivo. Nelas, o tema é o sofrimento amoroso que pode ser motivado pela morte ou pelo abandono e desdém do amado como na voz feminina do fragmento do poema citado:

Ai flores, ai flores do verde pino, se sabedes novas do meu amigo?

Ai Deus, e u é?

Ai flores, ai flores do verde ramo, se sabedes novas do meu amado?

Ai Deus, e u é?

Se sabedes novas do meu amigo, aquel que mentiu do que pôs conmigo?

Ai Deus, e u é?

Há um lamento que se dirige à natureza, às flores. O professor, com auxílio de informações sobre o período histórico pode tecer comentários mais aprofundados sobre a lírica trovadoresca e o contexto histórico, e trabalhar com a questão da variante diacrônica, recuperando a relação indissociável entre forma e conteúdo, constitutiva dos textos literários.

Paralelamente, nossa sugestão é a de apresentar um poema do Romantismo brasileiro, que, além de estar presente nos manuais de literatura, também é facilmente encontrável nas páginas da Internet ${ }^{10}$ : "Leito de Folhas Verdes", de Gonçalves Dias. Ainda que bastante mais elaborado, o poema filia-se à tradição das cantigas de amigo.

O poema, nos moldes do Romantismo, tem como pano de fundo a natureza que participa dos sentimentos do enunciador, essa voz feminina que se lamenta da

9 Basta lembrar, para os alunos, algumas composições de Chico Buarque de Holanda.

10 Sugerimos aqui o Jornal de Poesia, em que é possível encontrar vários poetas além de Gonçalves Dias: <http://www.jornaldepoesia.jor.br/gdias02.html\#leito>. 
Linha D'Água (Online), São Paulo, v. 29, n. 1, p. 85-102, jun. 2016

ausência do amado. O professor, juntamente com seus alunos, pode observar o vocabulário do poema, todo preso a elementos da natureza que se reiteram (bosque, folhas, flores, brisa, sol) e palavras de origem indígena (Jatir, arasoia) que remetem ao período romântico no Brasil. Ainda no que se refere às palavras, é importante notar-se as metáforas sempre inspiradas na natureza, como se observa neste exemplo da quinta estrofe:
A flor que desabrocha ao romper d'alva
Um só giro do sol, não mais, vegeta:
Eu sou aquela flor que espero ainda
Doce raio do sol que me dê vida.

Ao comparar, mesmo que brevemente, ao poema anterior, é interessante marcar que o apelo da índia, diferentemente da voz feminina nas cantigas de amigo, não é mais dirigido às flores ou a Deus, mas ao próprio amado "Por que tardas, Jatir, que tanto a custo/ À voz do meu amor moves teus passos?" - o que confere ao discurso um tom mais sensual, com uma dose de ousadia feminina, apesar do lamento e da atmosfera romântica, parece existir um menor grau de submissão da mulher ao amado. A espera da amada de Jatir é ansiosa e legítima, segundo a voz feminina que a enuncia:

Sejam vales ou montes, lago ou terra,
Onde quer que tu vás, ou dia ou noite,
Vai seguindo após ti meu pensamento;
Outro amor nunca tive: és meu, sou tua!

Ela demonstra nos versos a relação entre eles, mas sua espera não é recompensada. Jatir não conversa com a amada, tal como na cantiga de amigo; elas falam sem serem ouvidas. Será o amor uma ilusão?

No século XX, com o maior desenvolvimento das zonas urbanas e com os novos papéis da mulher na sociedade, o cenário dos versos também se desloca para os prédios, ruas com carros, sons pouco harmoniosos e personagens da cidade. Essa nova temática se constrói pela escolha vocabular (palavras antes alheias à poesia), pelos ritmos apressados tanto da prosa quanto da poesia - ambos entrecortados, em frases breves.

Assim é em "As penélopes urbanas não têm ajuda dos deuses"(MELO,1979), que, para além de uma intertextualidade temática, remete a todo um conhecimento que será necessário aos alunos para uma melhor leitura do lamento da mulher. 
Linha D'Água (Online), São Paulo, v. 29, n. 1, p. 85-102, jun. 2016

A sugestão é que se deixe de lado, num primeiro momento, o título do poema, se faça uma leitura denotativa em relação ao vocabulário e a estrutura sintática do poema; depois, uma busca de contrastá-lo com os dois anteriores e, por fim, conversar sobre as figuras de Penélope e de Ulisses para focalizar a atitude da mulher que externa seu sofrimento neste poema:

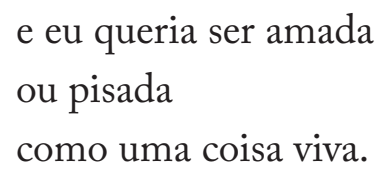

Há um simulacro de resignação nos versos finais, quando o eu lírico feminino se representa como coisa. $\mathrm{O}$ mesmo nome genérico que aparecera também na primeira estrofe e, nesse caso, se referindo a um fazer sempre igual, a uma mesmice:

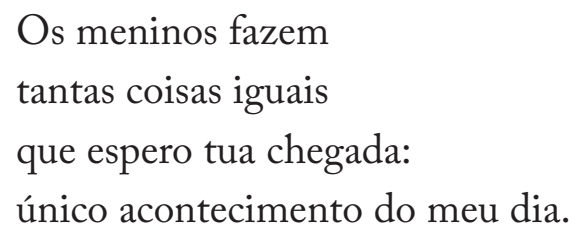

É como se esse eu lírico soltasse um grito em meio à atmosfera sufocante do lar. Há, na voz desse eu lírico, uma imensa intensidade dramática, quando a mulher apresenta a volta do amado como acontecimento único do seu dia. É uma relação de espera como nos outros poemas; agora, mais agônica, visto que o amado chega, mas não para ela. Nela e no seu lamento se espelha o desgaste das relações amorosas.

Se compararmos os poemas, observaremos mudanças significativas principalmente no vocabulário, pois a natureza saiu de cena, surgindo o cotidiano, a casa, os filhos. São colocadas lado a lado palavras triviais (trinco/ é aberto devagar) de cenas do cotidiano e imagens menos comuns (A noite já devorou/ tuas palavras maduras). Há, ainda, uma mudança no ritmo, marcado por versos curtos e heterométricos.

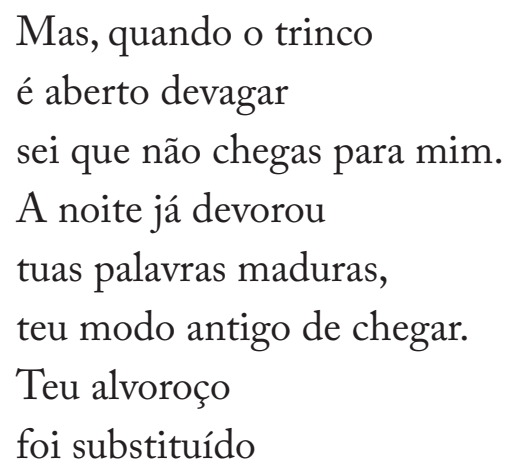


Linha D'Água (Online), São Paulo, v. 29, n. 1, p. 85-102, jun. 2016

por um certo respeito
pelas coisas distantes,

A relação intertextual, marcada no título, já disfórica, projeta a imagem de uma Penélope urbana cuja espera não tem final feliz. Tal como Penélope da Odisseia, a urbana aguarda, porém, como ela mesma afirma ao usar a conjunção adversativa (mas), a chegada do amado não representa a satisfação dos seus desejos; é a constatação de que o mundo definitivamente o afastou dela. E tal como a amada do leito de folhas verdes, o verdadeiro encontro não ocorre.

$\mathrm{Na}$ Cantiga de amigo, o eu lírico feminino clama a Deus; no "Leito de folhas verdes", o clamor se dirige ao amado que não vem (porém a esperança persiste), mas "As penélopes urbanas não têm ajuda dos deuses", então, qualquer dimensão redentora é abandonada. Será essa a imagem de mulher dos nossos tempos? A temática do feminino pode ser discutida como se apontou no caso da crônica de Otto Lara Resende com o apoio de outros textos de esferas diversas, permitindo uma abertura para a compreensão do papel do literário na constituição e interpretação do real.

\section{A modo de conclusão}

Nos textos literários, como foi possível perceber pelos comentários, ainda que ligeiros, que cada um dos níveis linguísticos colabora para a constituição dos sentidos, que são, assim, construídos de modos diversos em cada uma das épocas. Debruçarse sobre as escolhas lexicais, procurar por significados deixados de lado; identificar os processos linguísticos que constroem os poemas; apontar e comparar as figuras de linguagem e de sonoridade que caracterizam a enunciação e os enunciadores é desvendar como cada uma dessas épocas tratou dos mesmos temas.

A forma de abordagem proposta, ainda que não enfatize os períodos da história literária, não se aparta dela, uma vez que notamos a necessidade de considerarse o contexto de produção. Também salientamos que nossas observações sobre os textos comentados são, apenas, o início de um trabalho com cada um deles. Toda a construção linguística dos efeitos de sentido deve ser considerada pelo professor, pois o domínio de uma leitura mais proficiente do texto literário conduzirá o aluno a uma melhor compreensão e maior capacidade de reflexão sobre a sua história e seu contexto social. O professor fará suas escolhas e aprofundará as observações de acordo com seus objetivos e com a recepção de seus alunos.

Acrescente-se que o fato de termos nos referido a textos de menor extensão relaciona-se com o espaço deste artigo e com as possibilidades de um trabalho inicial em sala de aula. A leitura extraclasse dos grandes romances, consagrados pela 
Linha D'Água (Online), São Paulo, v. 29, n. 1, p. 85-102, jun. 2016

tradição não deve ser posta à margem, como também não se pode abandonar os processos de sistematização que, acreditamos, deva ser uma etapa posterior àquela do corpo a corpo com os textos, na qual língua e literatura caminham de mãos dadas.

Não deixar que esse diálogo com os textos - memória viva - se silencie é uma das tarefas do professor. Como um espelho diante de outro, as imagens se multiplicam em mil e uma, mostrando que "há mais mistérios entre o céu e a Terra do que supõe a nossa vã filosofia”, como diria Hamlet e isso pode ser um caminho ou uma janela para nossos alunos.

\section{Referências}

ALFARO, María Jesús Martínez. Intertextuality: Origins and Development of the Concept. In: Atlantis. vol. 18, n. 1/2 (Junio - Diciembre 1996), p. 268-285.

ANDRADE, Carlos Drummond de. Cota zero e A noite dissolve os homens. In: Obra completa: poesia e prosa. Rio de Janeiro: Nova Aguilar, 1988.

BENTES, Anna Christina Bentes; KOCH, Ingedore Villaça; CAVALCANTE, Mônica Magalhães. Intertextualidade: diálogos possíveis. São Paulo: Cortez, 2012.

BILAC, Olavo. Pátria. Disponível em: <http://pt.poesia.wikia.com/wiki/P\%C3\%A1tria_(Olavo_Bilac)>. Acesso em 06 abr. 2014.

CHARADEAU, Patrick; MAINGUENEAU, Dominique. Dicionário de análise do discurso. Coordenação de tradução: Fabiana Komesu. São Paulo: Contexto, 2004.

COSSON, Rildo. Letramento Literário - teoria e prática. São Paulo: Contexto, 2006.

KOCH, Ingedore Villaça; ELIAS, Vanda Maria. Ler e compreender: os sentidos do texto. São Paulo: Contexto, 2006.

KRISTEVA, Julia. Introdução à semanálise. Tradução de Lúcia Helena França Ferraz. São Paulo: Perspectiva, 1979.

LAJOLO, Marisa. Do mundo da leitura para a leitura do mundo. São Paulo: Ática, 1993. . O texto não é pretexto. In: Leitura em crise na escola. Porto Alegre: Mercado Aberto, 1982. 
Linha D'Água (Online), São Paulo, v. 29, n. 1, p. 85-102, jun. 2016

MARCUSCHI, Luiz Antônio. Gêneros textuais: definição e funcionalidade. In: DIONÍSIO, Angela Paiva; MACHADO, Anna Rachel; BEZERRA, Maria Auxiliadora. (orgs.). Gêneros textuais e ensino. São Paulo: Contexto, 2010. (Coleção Estratégias de Ensino, 18).

MELO, Alberto da Cunha. As penélopes urbanas não têm ajuda dos deuses. In: Noticiário. Recife: Edições Pirata, 1979.

RESENDE, Otto Lara. Cota zero. In: Folha de São Paulo, 1, 2, 24 jan. 1992. Disponível em http://acervo.folha.uol.com.br/fsp/1992/01/24/2\#>. Acesso em 14 mar. 2016.

RIFATERRE, Michael. Le poème comme représentation. In: Poétique no. 4, Paris: Seuil, 1970, p. 401-419.

STAIGER, Emil. Conceitos fundamentais da Poética. Tradução de Celeste Aída Galeão; Revisão da parte grega de Rosa Carino Louro. Rio de Janeiro: Tempo Brasileiro, 1975.

Recebido: $15 / 03 / 2016$

Aprovado: 19/04/2016 